\title{
The practical library manager.
}

Bruce E Massis

New York: Haworth Information, 2003. 149p.

ISBN 07890 I 7652 (hb); ISBN 07890 I 7660 (sb)

Cost: US\$34.95 (hb); US\$24.95 (sb)

There is a need for guidance for those faced with the challenge of day-to-day administration and running of small to medium-size libraries of all kinds. The education of library and information science workers at the professional level is usually pitched at a general level, seeking to equip new entrants to the career with sufficient knowledge of principles so that they can make informed decisions as needs change. Some knowledge of practice is acquired through fieldwork but it is during the period of introduction to a new job, subsequent mentoring and practice that most detailed practical knowledge is acquired. Little wonder, then, that there is a market for a guide of this kind.

This book does not attempt to address the needs of the market in Southern Africa or, indeed, anywhere outside the United States of America; however, it is a useful guide to the issues such a guide should cover and its practical approach, with clear guidelines and the use of copious "bullet-point" lists is a model of good presentation.

Massis writes in a direct, personal, style about American public service that may challenge many of our conceptions of culture "across the pond":

"For the decades leading up to the new millennium, the phrase 'public service' clearly appeared to be misapplied to the American workforce. It frequently appeared that those in general public service positions provided a poor quality of service matched only by a genera! abhorrence of the public they were 'sworn' to serve. One did not have to attempt anything more exotic than a visit to the local Department of Motor Vehicles to recognise that the only thing many public service employees despised more than the service was the public" (page I).

Thus it is that planning, implementing and evaluating a training programme for library staff is seen by Massis as being the greatest challenge facing library managers. In terms of our South African culture it must also be the point of challenge - but not because of an antipathy to the concept of public service. As a recent immigrant from the United Kingdom, I have, with few exceptions, been impressed by the standard of service, general courtesy and care expressed in shops and other public service points in South Africa. The challenge is to design staff training that takes people beyond the boundaries that are still part of the collective mindset of this culture.

The influence of Information and Communication Technology (ICT) is also seen as a transforming element that must be managed and accommodated in training. Here the reviewer takes issue with Massis: "transformation" is a teleological concept, meaning that we are sure of the beginning and the end points of the process. The adoption and development of ICTs seems, by contrast, to be an agent of change, the impact of which we have no clear view. The World Wide Web is barely ten years old, at least in its public manifestation: few of its effects were perceived when it was first launched. Thus we have the challenge of designing and re-designing our staffing structures and staff training to accommodate and to shape new facilities and services that we can create.

Many of the ideas in this book will be useful once suitable parallels in Southern Africa have been identified. Will someone please write a training manual to satisfy our needs?

Reviewed by: Peter G. Underwood, Professor of Librarianship, University of Cape Town, South Africa

Tel: 0216503091

E-mail: pgunderwood@ched.uct.ac.za

SA Jnl Libs \& Info Sci 2003, 69(2) 